\title{
Recepción y enfoques historiográficos del pensamiento político en la India contemporánea
}

\author{
Historiographic reception \\ and approaches to political \\ thought in contemporary India
}

\author{
MARIO LÓPEZ AREU*
}

Resumen: La teoría política contemporánea está dominada por las ideas y los valores del pensamiento occidental moderno; sin embargo, tras el proceso de descolonización en Asia y África se ha abierto un importante debate acerca de la continuidad y la legitimidad de esas ideas en sociedades poscoloniales. Se presentan las dos principales corrientes historiográficas que conforman esta discusión en la ciencia política de la India contemporánea a través del análisis de sus principales autores y obras: la corriente hermenéutica, que defiende que el pensamiento político indio moderno es resultado de un proceso de fusión entre conceptos y valores occidentales con las ideas indias tradicionales, y la corriente indigenista, que aboga por el desarrollo de una ciencia política india autónoma respecto a las ideas y los valores occidentales.

Palabras clave: India; modernidad; poscolonialismo; escuela de Cambridge; estudios subalternos.

Abstract: Contemporary political theory is dominated by the ideas and values of modern Western thought. However, following the decolonization process in Asia and Africa an important debate is tak-

Recepción: 9 de agosto de 2017. / Aceptación: 29 de noviembre de 2017.

* Universidad Pontificia de Comillas, mario.l.areu@gmail.com 
ing place regarding the continuity and legitimacy of those same concepts in postcolonial societies. This paper analyses that debate within Indian political science, examining how Western ideas have interacted with those from the Indian tradition to shape modern-day Indian political thought and the contemporary Indian state. The paper presents the main historiographical approaches present in this debate through an analysis of their main authors and works: the hermeneutic approach, which defends the notion that modern Indian political thought derives from a process of encounter between Western and Indian traditions, and the indigenist approach, which advocates for the development of an Indian political science discipline autonomous of Western ideas and values.

Kew words: India; modernity; post-colonialism; Cambridge School; subaltern studies.

\section{Introducción}

Es indudable que la modernidad política como tal no puede ser concebida sin utilizar los conceptos políticos occidentales. La teoría política contemporánea está construida y dominada por ideas y valores que emergen de la tradición occidental. El Estado, la democracia o el secularismo son conceptos que nacen y se desarrollan dentro de ella. Esta situación es lógica por la posición históricamente dominante de Occidente, que ha exportado sus valores e instituciones al resto del mundo, sea a través del imperialismo o del fenómeno de la globalización.

Sin embargo, a mediados del siglo xx la ola de movimientos anticolonialistas en Asia y África dio lugar a un intenso debate intelectual sobre los procesos de recepción y asimilación de las epistemologías y las ontologías políticas occidentales por parte de los sistemas sociopolíticos de estas regiones. $\mathrm{La}$ discusión se ha centrado en cómo la implantación de sistemas políticos fundamentados en instituciones y valores normativos occidentales, ajenos a la experiencia vital de la población local, es legitimada en un contexto poscolonial. Si la modernidad occidental es impuesta por una fuerza invasora ilegítima, una vez que ésta es expulsada, ¿qué relación debe existir entre 
las ideas que sustentaron y justificaron su régimen y las autóctonas?

El debate ha sido particularmente fructífero dentro de la historia de las ideas en India. Este artículo ofrece una radiogra$f^{\prime}$ a de las principales corrientes historiográficas actuales que se han sumergido en el análisis de la recepción de las ideas políticas occidentales en la India contemporánea. Esto permitirá conocer los distintos enfoques y metodologías que se utilizan en las ciencias sociales para comprender la relación entre ideas políticas occidentales y agencia intelectual india en el desarrollo de una modernidad política poscolonial estable y democrática.

El texto se divide en dos partes: un análisis del origen de la ciencia política como campo de estudio académico en India, donde se verá que nace de un proceso contestatario respecto a las presuposiciones orientalistas sobre la civilización india del pensamiento occidental; $y$ un recorrido de las distintas escuelas historiográficas que han tratado la relación de fuerzas entre las ideas y los valores políticos occidentales y las ideas autóctonas indias en la formación del pensamiento político indio moderno, el cual ha determinado la forma política de la India independiente.

\section{Los orígenes de la ciencia política en India}

Hay diversas tesis sobre cuándo y cómo la teoría política se establece como campo de estudio en India.

En un volumen de publicación reciente, Pradip Kumar Datta y Sanjay Palshikar defienden que el pensamiento político indio moderno nace de las estructuras epistemológicas y ontológicas del pensamiento orientalista occidental de finales del siglo XIX, específicamente como respuesta, e incluso resistencia, a sus prejuicios. El hito histórico que marca el nacimiento de la teoría política moderna como tal a comienzos del siglo Xx es la publicación, en 1905, de partes del Arthashastra por Pandit Shamasastry (Datta y Palshikar, 2013, p. 2).

El pensamiento orientalista occidental, en términos generales, argumenta que India no posee pensamiento político per $s e$, sino que la religión es la principal estructuradora de la so- 
ciedad y la administradora del poder político. En ese sentido, el orientalismo señala el sistema de castas como el ejemplo más evidente para ilustrar su tesis (por ejemplo, Dumont, 1980 y Heesterman, 1985). En términos de la tradición hindú de pensamiento político, los orientalistas abogarían por la supremacía del dharma en la organización de la sociedad india. El dharma es un concepto complejo, pero que puede ser interpretado, según Bikhu Parekh, como "aquello que mantiene a una sociedad unida”; esto implica la aceptación y la realización, por parte de los individuos y los grupos dentro de una sociedad, de sus deberes cívicos (Parekh, 1986, p. 18). Sin embargo, el dharma no es el único principio de organización social en la tradición política hindú, sino que se complementa por un segundo principio, el del artha. El artha es la organización y los mecanismos de gobierno eficientes, es decir, el arte de la gobernanza. El artha es el dispositivo necesario para mantener el dharma.

La importancia de la publicación, en 1905, de partes del $A r$ thashastra radica en que se demostró documentalmente la existencia de un tratado que reflexionaba sólo sobre el arte de gobernar y en el que el dharma y la religión ocupaban un lugar marginal. ${ }^{1}$ La publicación, por ende, contradecía la tesis orientalista de la ausencia de una corriente de reflexión política. Tras el descubrimiento y la publicación del tratado por parte de Shamasastry - prosiguen Datta y Palshikar-, la ciencia política india continuó cimentándose entre 1920 y 1940 con la divulgación de varias investigaciones que expanden el conocimiento sobre el pensamiento político indio antiguo (por ejemplo, Bhandarkar, 1929; Jayaswal, 2005 y Sarkar, 1939). En particular, destaca la diferenciación entre las escuelas del Dharmashastra y del Arthashastra, y la profundización en el desarrollo de la segunda, es decir, de las ideas del arte del gobierno, hasta entonces marginada académicamente. Al mismo tiempo, se crea un consenso alrededor de la traducción del término occidental "política" como rajniti (raj se traduce como gobierno; niti, co-

${ }^{1}$ El Arthashastra o "Tratado sobre la ganancia material" es atribuido a Kautilya, ministro de Chandragupta Maurya (340 a.e.c.-298 a.e.c.). Kautilya define el tratado como la ciencia concerniente a los medios para adquirir y mantener "la Tierra", y se centra más en las prácticas de gobierno y administración que en la teorización política (Dandekar, 1998, p. 235). 
mo políticas) y se define como el arte de gobernar, en lo que se refiere a instrucciones prácticas de gobierno en lugar de la teorización política (Datta y Palshikar, 2013, p. 4).

Una segunda tesis sobre el origen de la ciencia política india es la desarrollada por Sudipta Kaviraj, que en su introducción al volumen Politics in India lo sitúa en la década de 1930. Según él, en sus primeros años la ciencia política se centra en el estudio del derecho constitucional. Con el movimiento nacionalista en esos años avanzando hacia la independencia, o al menos hacia la autonomía política dentro del Imperio británico, la estructuración de un futuro Estado indio centra la atención académica de los politólogos; para Kaviraj (1997a, p. 4), hay un "optimismo jurídico" acerca de las transformaciones sociales que se pueden alcanzar a través de un adecuado texto constitucional, como la abolición del sistema de castas, el desarrollo económico o la secularización del país.

Tanto el análisis de Datta y Palshikar como el de Kaviraj coinciden en destacar que el origen y el desarrollo de la ciencia política en India van inexorablemente unidos al proyecto nacionalista. Y es que, como afirma Ananya Vajpeyi: "la lucha por la libertad de la India es el firmamento contra el cual podemos ver el horizonte de lo político" (2012, p. xi).

Si Datta y Palshikar (2013, p. 5) sitúan el origen en un contexto de resistencia y contestación de las tesis orientalistas occidentales, defienden que su posterior desarrollo convirtió a la ciencia política india en un vehículo de justificación y apoyo a la tesis de ese país como una entidad histórica estable y con fronteras, tanto geográficas como sociales, claramente definidas. De esta forma, la ciencia política se convirtió en una herramienta política más al servicio del movimiento nacionalista y se preocupó de proveer de argumentos a su discurso. En los primeros años se promovió sobre todo el pensamiento hindú, como en el caso del Arthashastra, y se ignoraron otras tradiciones de pensamiento indias, como la islámica. La razón era la necesidad de promover la cohesión intelectual y el origen único y exclusivo que demanda cualquier narrativa nacionalista. Más adelante, cuando la homogeneidad discursiva se vio contradicha por la irrupción de nuevos grupos identitarios dentro del movimiento nacionalista, como el musulmán o el dalit (into- 
cables), la ciencia política hizo frente a tal desafío normalizando la diferencia con base en dos principios básicos: primero, la idea de la unidad en la diversidad -India como proyecto de nación multicultural-y, segundo, la independencia respecto al Imperio británico como objetivo común de los distintos fundadores de India a pesar de sus diferencias ideológicas e identitarias.

Kaviraj también ve un sesgo nacionalista en los orígenes la ciencia política india. Sin embargo, mientras que Datta y Palshikar fundamentan su tesis en la discontinuidad entre el pensamiento colonialista-orientalista y el nacionalista, Kaviraj (1997a, p. 31) destaca el continuismo entre ambos con base en la importancia que los dos dan a las estructuras sociales tradicionales. Para Kaviraj, hay un consenso entre las élites colonialista y nacionalista acerca de la inmutabilidad de estas estructuras como un grupo de prácticas relativamente estáticas y permanentes. Para el movimiento nacionalista, la eliminación de dichas estructuras tradicionales era un requerimiento fundamental para la transformación de India en una sociedad moderna. Como el cambio social no podía ocurrir endógenamente por la resistencia de las prácticas tradicionales, era necesario forzarlo a través de una Constitución transformadora y modernizadora. La ciencia política, por tanto, se ve arrastrada por el "optimismo legal" del nacionalismo y se centra en el derecho constitucional como su principal campo de estudio.

Como se observa, en sus orígenes, a principios del siglo xx, la ciencia política moderna india como disciplina académica ve su desarrollo moldeado por el nacionalismo, al que equipa con argumentos y valores normativos. Ese nacionalismo es oficialista, representado por el Congreso Nacional Indio y, en particular, por el proyecto político del primer líder de la India independiente, Jawaharlal Nehru, en el que encarna la transformación de India en un Estado moderno de molde occidental, lo que supone dos cambios principales: uno es la planificación económica y la industrialización para alcanzar el desarrollo económico, y el segundo es la democracia secular para garantizar la estabilidad religiosa y la igualdad de los ciudadanos. A dicho proyecto nacional se le ha llamado "nacionalismo nehruviano" o "consenso nehruviano" (Khilnani, 1997). 
El declive del nacionalismo nehruviano y del consenso alrededor de éste supone una verdadera revolución en la ciencia política en India. La muerte de Nehru en 1964 dio lugar al surgimiento de voces discordantes con el discurso oficialista, tanto dentro como fuera del Congreso, que ofrecieron una mayor pluralidad de visiones sobre el futuro del Estado-nación indio. Dentro de la ciencia política, distintas corrientes desafiaron la historiografía oficialista del nacionalismo indio y cuestionaron la validez y la legitimidad de los principios políticos que sustentaban ese proyecto en el contexto social, cultural y religioso indio.

\section{Corrientes historiográficas en la ciencia política india contemporánea}

La ciencia política como disciplina académica en la India contemporánea está fuertemente unida al análisis del modelo de Estado-nación nacido de la independencia y del impacto que ha tenido a la hora de moldear la realidad sociopolítica poscolonial. Ese punto de partida supone que la atención de la disciplina se haya centrado en tres cuestiones fundamentales. Primero, la recepción de las ideas occidentales introducidas por los británicos por parte de las élites intelectuales indias; segundo, la relación de fuerzas entre esas ideas y las autóctonas en el resultante pensamiento moderno indio que moldeó el Estadonación posindependencia; y, tercero, la legitimidad de dicha modernidad y, por ende, del Estado-nación, para la sociedad india en general.

Diversas escuelas y enfoques han presentado sus propias tesis acerca de esta relación de fuerzas intelectual. Estas tesis historiográficas han tenido una importante influencia en el desarrollo del debate en la ciencia política sobre la legitimidad social del Estado moderno en India.

\section{La corriente bermenéutica}

Dentro de la corriente hermenéutica se agrupa a un importante número de académicos de dos escuelas: la de Cambridge y la 
subalterna, y un enfoque: el estructuralista. Entre estas escuelas hay grandes diferencias de criterio y metodología al estudiar el pensamiento político indio moderno. Sin embargo, desde mi punto de vista, hay un importante punto en común: la aceptación de que las ideas políticas indias modernas son producto de la interacción entre distintas tradiciones epistemológicas que han cohabitado en India durante diferentes épocas. Esto las distingue fundamentalmente de la segunda corriente, que analizaré más adelante: la indigenista, que rechaza tal fusión.

\section{a) La escuela de Cambridge}

La escuela de Cambridge se originó a finales de la década de 1970 y entre sus principales autores destacan Christopher Bayly, Shruti Kapila, Faisal Devji y Sumit Guha. Aunque la historia de las ideas políticas en India no es su única área de estudio, sí es la principal, en particular debido a la crítica que hacen a la marginación de ésta a favor de la historia social, la de la relación entre política, economía y sociedad (Kapila, 2010, p. v). Uno de sus objetivos básicos es comprender cómo las ideas políticas viajaron a, desde y dentro de India y cómo fueron recibidas y reinterpretadas por las élites intelectuales indias (Bayly, 2010, p. 150).

La escuela de Cambridge destaca principalmente por su tesis de carácter continuista de la transición sociohistórica de la India precolonial a la colonial y, más tarde, a la moderna, incluida la continuidad intelectual. Christopher Bayly (2012, p. 8) defiende que todo lenguaje político moderno es derivativo y mezcla discursos globales y locales, por ello la escuela rechaza tanto el esencialismo intelectual que defiende la corriente indigenista como el concepto de historia intelectual independiente de la historia social; en esto coincide con la otra famosa escuela de Cambridge, la del análisis discursivo de Quentin Skinner y John Pocock. ${ }^{2}$ Lo importante para ellos, según Bayly (2012,

${ }^{2}$ En la introducción al volumen An intellectual history for India, Kapila cita de manera destacada a Skinner: "La única historia de las ideas que se puede escribir son las historias de sus usos en el discurso" (2010, p. v). En el mismo volumen, Bayly cita la obra de Pocock El momento maquiavélico como un clásico sobre el viaje de las ideas de una sociedad a otra (2010, p. 150). 
p. 24), es saber por qué algunas ideas eran más relevantes que otras en distintos periodos históricos.

Distintas obras seminales destacan de esta escuela. Una de las principales es Empire and information: Intelligence gathering and social communication in India, 1780-1870, de C. A. Bayly (1996), en la que defiende la importancia del conocimiento recibido por los británicos de los gobernadores mogoles de la India precolonial en la construcción del posterior Estado colonial. Bayly destaca que hasta 1850 las fronteras geográficas coloniales y el modelo de gobernanza británico en India están claramente influidos por el propio conocimiento y las prácticas políticas, sociales y económicas mogoles. Al llegar a un nuevo territorio como India, los británicos establecieron alianzas con los agentes políticos y económicos instituidos y aprendieron de ellos los mecanismos y las estrategias de negociación necesarios para establecer relaciones mercantiles en el territorio. Ese proceso de aprendizaje y adaptación —explica Bayly - supuso una influencia significativa india en las prácticas y las ideas políticas británicas coloniales. Con base en esta evidencia histórica, Bayly argumenta que la historiografía tradicional omite la importancia de los procesos locales de cambio social, político y económico en la historia moderna del subcontinente; es decir, pone demasiado énfasis en la agencia colonial, la influencia que los británicos tuvieron en las transformaciones sociopolíticas en India, y muy poca en la agencia india, es decir, en las élites indígenas tanto dentro como fuera de las estructuras coloniales.

En 2012, Bayly publicó Recovering liberties: Indian thought in the age of liberalism and empire, donde profundiza en la tesis de la escuela sobre la recepción y la domesticación de ideas políticas occidentales, en este caso el liberalismo, por parte de la élite intelectual india. Su principal argumento es que existe una continuidad intelectual entre el liberalismo occidental y el indio; sin embargo, no encontramos en ella una simple transposición conceptual, sino que intelectuales indios, como Rammohan Roy (1772-1833) o Dadabhai Naoroji (1825-1917), adaptaron las ideas liberales occidentales a la realidad social india, defendiendo la abolición del sistema de castas y la igualdad entre hombres y mujeres, y al mismo tiempo utilizaron 
los principios liberales para combatir intelectualmente la opresión colonial y abogar por mayores libertades políticas y sociales para la población india; por ejemplo, al sostener que la democracia o que una sociedad civil autónoma del Estado eran valores intrínsecos al liberalismo (Bayly, 2012, p. 343).

Otra investigación digna de señalarse es "Civil authority and due process: Colonial criminal justice in the Banaras zamindari, 1781-1795”, de Radhika Singha (1998), artículo en el cual examina cómo los británicos desarrollaron el sistema judicial colonial. Singha defiende la introducción de nuevos conceptos jurídicos, como el de derecho soberano, que no tenían precedente epistemológico en la sociedad india, para ligarlos a las nociones y tradiciones legales conocidas. Mientras que el derecho occidental se basa en el principio de universalidad, en que el individuo es aislado de su contexto social para que la aplicación de la ley sea igual para todas las personas en todo el territorio estatal, el derecho indio parte del principio de particularidad, donde el contexto social y las asociaciones "naturales" del individuo, como la familia, la religión, la casta o la localidad, son determinantes a la hora de aplicar la ley, ya que el comportamiento individual está mediado por circunstancias derivadas de esas tradiciones. Por ello los británicos, cuando codificaron el derecho civil indio, crearon dos códigos separados, uno para los musulmanes y otro para los hindúes. Es decir, buscaron un punto medio entre el principio de universalidad occidental (la codificación) y el de la particularidad indio (el contexto religioso).

En suma, la tesis sobre el origen de la modernidad política india de la escuela de Cambridge resalta que la élite intelectual india, durante el periodo colonialista, poseía voluntad; es decir, no se limitó a recibir pasivamente las ideas de la modernidad occidental importada por los británicos. En su lugar, escogió y desechó de manera consciente aquellas ideas políticas que creyó que ayudarían a transformar India social y políticamente. Y es a través de ese proceso de selección, reconceptualización y descarte de ideas como la élite construyó un pensamiento político indio moderno, que es a un tiempo derivativo y único. 


\section{b) Los estudios subalternos}

Los estudios subalternos emergen formalmente a comienzos de la década de 1980 y su germen fue el colectivo académico del mismo nombre, entre cuyos principales miembros destacan Ranajit Guha, Partha Chatterjee, Dipesh Chakrabarty y David Arnold. El colectivo fue liderado por Ranajit Guha, que en aquellos momentos era profesor de historia en la Universidad de Sussex, en el Reino Unido. En 1982, el colectivo publicó el primer volumen de una larga serie de recopilaciones de ensayos bajo el título Subaltern Studies: Writings on South Asian history and society. En ese primer volumen de la serie, Guha presentó un breve manifiesto de 16 puntos en que detallaba los principios de los estudios subalternos.

La tesis principal de Guha, razón de ser de los estudios subalternos, es que "la historiografía del nacionalismo indio ha estado dominada durante largo tiempo por el elitismo: el elitismo colonial y el elitismo nacionalista-burgués" (Guha, 1982, p. 1). Guha subraya que ambas formas de elitismo son producto ideológico del control británico sobre India y, lo que es más, que tal ideología colonialista ha sobrevivido a la transición política del colonialismo a la independencia y "ha sido asimilada como neocolonialismo y neonacionalismo en el discurso [contemporáneo] en Gran Bretaña e India respectivamente" (1982, p. 1). En otras palabras, para la escuela subalterna, los análisis del pasado reciente del subcontinente, en particular respecto al surgimiento del colonialismo y el nacionalismo, fueron producto y propagación de paradigmas políticos elitistas, tanto británicos como indios (Pinch, 1999, p. 391). La naturaleza elitista de estos paradigmas, o narrativas discursivas, margina la contribución del pueblo, lo que la escuela llama "las clases subalternas", en la construcción del nacionalismo indio. ${ }^{3}$ En el manifiesto,

${ }^{3}$ La definición de clases subalternas que utiliza Guha, y posteriormente el grupo de estudios subalternos en su conjunto, indica la influencia de la obra del pensador marxista italiano Antonio Gramsci, quien, en sus "Notas sobre historia italiana", define como subalternos a aquellos grupos sociales subordinados a las actividades de los grupos dominantes (Gramsci, 2003, p. 55). Gramsci también aboga por que el historiador investigue las iniciativas políticas que los grupos subalternos realizan de manera independiente de las élites dominantes, porque poseen un importante valor histórico; ésa es la función que busca realizar la escuela. Para un debate más detallado 
Guha (1982, p. 3) destaca que, para la historiografía elitista, la función de las masas en el movimiento nacionalista se integra ya sea de manera negativa, como un problema de ley y orden público debido a su participación en revueltas, boicots, etc., o de manera positiva, como respuesta al carisma de las élites nacionalistas. Los estudios subalternos, por tanto, buscan rescatar las narrativas políticas subalternas a través de una relectura radical de la evidencia histórica "contaminada" por el discurso elitista y de poder político (Pinch, 1999, p. 391).

Además del manifiesto fundacional del colectivo, Guha ha publicado otro par de obras de referencia en el desarrollo del enfoque subalterno sobre el origen de la modernidad política india. Su libro Elementary aspects of peasant insurgency in colonial India (1983) está considerado como un clásico pionero de los estudios subalternos en el ámbito internacional. En esta obra, Guha analiza las relaciones de dominación y subordinación entre 1783 y 1900 en la India rural desde el punto de vista de los campesinos indios. Su tesis central es que las revueltas campesinas durante el periodo colonial no eran simples reacciones espontáneas ante injusticias puntuales, sino que representaban respuestas organizadas cuyo fin era producir un cambio político específico en las relaciones productivas entre campesinos y latifundistas. Guha añade que tales revueltas desembocaron en la creación de una conciencia subalterna cuya fuerza fue crucial para el apoyo de las masas al movimiento de resistencia que más tarde lideraría Gandhi (1983, p. 335). Es en este libro también donde desarrolla de manera más detallada lo que se entiende por identidad subalterna. Guha la define como un tipo de acción política autónoma de la esfera del poder político habitada por las élites y que existió desde antes del colonialismo y durante él. La esfera subalterna de pensamiento y acción no es primitiva, es decir, no es prepolítica, sino diferente a la elitista, centrada en la movilización de masas en contraste con la movilización parlamentaria y constitucionalista de la segunda. ${ }^{4}$

sobre grupos subalternos en Gramsci, véase su cuaderno 25, titulado "Al margen de la historia. Historia de los grupos sociales subalternos” (Gramsci, 2007).

${ }^{4}$ Aquí Guha critica la tesis marxista de Eric Hobsbawm, que en su obra Primitive rebels: Studies in archaic forms of social movement in the $19^{\text {th }}$ and $20^{\text {th }}$ centuries (1971) define al campesinado indio como prepolítico, es decir, niega su modernidad. 
El otro escrito notable de Guha es su artículo "Dominance without hegemony and its historiography" (1989), ensayo en el que desarrolla la segunda tesis fundamental de la escuela subalterna: que la dominación administrativa y económica de los británicos durante el periodo colonial no estuvo cimentada en una hegemonía política y cultural sobre la población india. ${ }^{5}$ Guha argumenta que los británicos, con el apoyo de la élite intelectual india, fracasaron en su intento de apropiarse del pasado conceptual del país para justificar el colonialismo con base en una narrativa liberal de progreso y libertad (1989, p. 210). Ilustra lo anterior mediante el análisis de la relación que se intentó desarrollar entre varios conceptos occidentales e indios. Un ejemplo es el de la equivalencia entre desarrollo (improvement) y dharma. Guha señala que la noción de dharma, entendida por la élite intelectual como virtud o deber moral, para las clases subalternas estaba fuertemente ligada a la idea del deber social de aceptar resignadamente la posición de uno dentro de la jerarquía del sistema de castas y estructuras de poder local. Guha apunta que la identificación de la élite nacionalista con un nacionalismo unido al concepto de dharma resultó en tensiones entre el campesinado pobre y los señores feudales, entre los miembros de las castas altas y los de las bajas dentro de la población hindú, y entre hindúes y musulmanes en general (1989, p. 246). Este intento de apropiación del pasado con el objetivo de crear una hegemonía ideológica alrededor del liberalismo no sólo fracasó, sino que fomentó la creación de fronteras políticas y culturales entre las élites colonialista y nacionalista y las clases subalternas. En conclusión, la tesis de Guha defiende que, a pesar de que los británicos primero y la élite nacionalista después consiguieron dominar el Estado indio, tal dominación no supuso la subyugación de todas las relaciones precapitalistas en la vida material y espiritual de la sociedad india, lo que desmiente que la narrativa de la élite nacionalista representara el sentir de toda la población $(1989$, p. 228).

${ }^{5}$ De nuevo es evidente la influencia del pensamiento de Gramsci en los estudios subalternos. El concepto de hegemonía es fundamental en la obra del pensador italiano, quien sostiene que la fuerza material no es suficiente para el liderazgo efectivo, sino que ésta debe ir acompañada de una hegemonía intelectual, moral y política (Gramsci, 2003, p. 59). El propio Guha hace referencia al pensador italiano en la nota 37 del ensayo. 
Además de Guha, cabe destacar a Partha Chatterjee como el otro gran autor que ha profundizado particularmente en el desarrollo teórico y metodológico de los estudios subalternos. Chatterjee es, al día de hoy, no sólo un referente fundamental de los estudios subalternos, sino también uno de los principales teóricos del pensamiento poscolonialista en el plano global. Su Nationalist thought and the colonial world: A derivative discourse (1986) es una obra de referencia para conocer el desarrollo de las ideas políticas en la India moderna desde un enfoque subalterno. Aunque desde una posición distinta, Chatterjee aborda la misma cuestión que preocupa a la escuela de Cambridge: la relación entre el origen del pensamiento político indio moderno y el grado de influencia del pensamiento occidental en éste y la interacción entre ambos.

El punto de partida de su análisis es una crítica a las pretensiones hegemónicas de la modernidad occidental y sus escuelas de pensamiento, tanto el liberalismo como el marxismo. Tras examinar las teorías de Ernest Gellner, Elie Kedourie, Anthony Smith y Benedict Anderson sobre el nacionalismo, Chatterjee (1986, p. 3) critica que, en sociedades coloniales, lo presenten como una herramienta en la lucha por la modernización de sociedades tradicionales, es decir, como un esfuerzo por alcanzar los ideales de la Ilustración occidental. Las conclusiones teóricas de estos autores occidentales se dividen en dos grupos. Por un lado, los liberales y marxistas llegan a conclusiones racionalistas; por otro, los conservadores extraen conclusiones relativistas que consideran que el nacionalismo como fuerza modernizadora fracasa en sociedades coloniales porque éstas no poseen las bases culturales necesarias para su consolidación. Chatterjee (1986, p. 11) critica el esencialismo de ambas posturas que defienden que nada más hay un camino hacia la modernidad y que ésta sólo es tal si sigue los estándares occidentales y que, por lo tanto, perpetúa la dominación colonial a través de la continuación de las ideas occidentales en el periodo poscolonial.

Para Chatterjee (1986, p. 40), el nacionalismo indio en el periodo colonial no es una simple herramienta vacía de contenido intelectual, como arguyen los teóricos occidentales; al contrario, el nacionalismo se convierte en un vehículo de desarrollo 
de ideas políticas autóctonas. Su análisis distingue dos partes dentro del nacionalismo; primera, sus reivindicaciones intelectuales, lo que llama la problemática, y, segunda, las estructuras de justificación de dichas reivindicaciones, la temática. Siguiendo la tradición teórica de la escuela subalterna, Chatterjee (1986, p. 38) defiende que la problemática contiene las legítimas ideas y reivindicaciones políticas de la población india, mientras que la temática es un discurso poblado de conceptos occidentales que utilizan las élites nacionalistas para la lucha dialéctica con el poder colonial. Sostiene que la historiografía y la ciencia política tradicionales en India han obviado el análisis de la problemática, dominado por las clases subalternas, a favor del de la temática, bajo control de las élites colonialistas y nacionalistas. Para él, las ideas contenidas en la problemática poseen una lógica, una epistemología y una ética que emergen de la tradición intelectual india, independientes de la tradición occidental importada por los colonialistas. ${ }^{6}$

La tesis de Chatterjee no es un argumento que busque defender el origen exclusivista del pensamiento político indio moderno, entendido como libre de influencia occidental. Chatterjee (1996, p. 43) escribe que el discurso y el lenguaje de la temática poseen una fuerte influencia en el desarrollo de las ideas conte nidas en la problemática, ya que su lógica y su estructura dialéctica limitan la identificación de posibles ideas y reivindicaciones políticas para el movimiento nacionalista, pues hace que aquellas que, desde el punto de vista de la batalla semántica, son consideradas como más viables, sean también más deseables, mientras que otras son ignoradas. La conclusión de Chatterjee es que el ámbito de la temática, el de las élites nacionalistas de raíz epistemológica occidental, influye decididamente en el desarrollo de la problemática o corpus de ideas que compone la modernidad intelectual india legítima. Para él, esto significa que mientras que hay un pensamiento político indio moderno ori-

${ }^{6}$ En su artículo "Whose imagined communities?” (1996), Chatterjee expande su tesis sobre la distinción entre problemática y temática. Redefine estos conceptos como dominio espiritual y material respectivamente. El primero está compuesto por las tradiciones y las epistemologías autóctonas indias y, por tanto, es impenetrable para el Estado colonial. El dominio espiritual, o problemática, es el germen de la resistencia intelectual frente al colonialismo, visto como ilegítimo, lógica, epistemológica y éticamente, por la población local. 
ginal, al mismo tiempo éste sigue influido y dominado, al menos en su forma más elitista, por el colonial-occidental.

En conclusión, los estudios subalternos han abogado por el estudio de las ideas políticas indias modernas como una esfera de conocimiento en sí misma; esto no supone un rechazo de las categorías políticas occidentales, pero sí un deseo de establecer una nueva relación de autonomía entre ellas. Para construir tal relación, este enfoque busca otorgar mayor centralidad a la contribución de las clases subalternas al desarrollo de la modernidad política india a través de su tratamiento como sujetos con una historia propia y con capacidad para desarrollar sus ideas políticas independientemente de la élite colonial y nacionalista (Das, 1989, p. 312).

\section{c) El estructuralismo de Sudipta Kaviraj}

Sudipta Kaviraj estuvo asociado durante muchos años a los estudios subalternos y, ciertamente, sus primeros escritos están fuertemente influidos por ellos. Sin embargo, con el tiempo su obra se distanció de ese enfoque y se acercó a posiciones estructuralistas que le permitieran desarrollar puentes epistemológicos entre las ideas políticas occidentales y las indias. En la introducción a su colección de ensayos The imaginary institution of India (2010, p. 2), Kaviraj explica el porqué de dicho distanciamiento. Ahí sostuvo que la constante acusación hermenéutica del enfoque subalterno a las ciencias sociales y los sistemas de conocimiento dominantes de ser "burgueses" resultó en una búsqueda incesante de una epistemología alternativa de las clases subalternas. Para Kaviraj (2010, p. 4), las consecuencias de esa dinámica son dos: que el término "burgués” se utiliza con gran imprecisión conceptual, lo que deriva en una acusación generalizada de elitista a cualquier tipo de sistema de conocimiento dominante; y que a menudo se minimiza la dificultad para construir una historiografía subalterna, en particular la de rescatar la evidencia histórica, encontrar un lenguaje que exprese su contenido legítimamente $y$, por último, teorizar sobre la base de esa perspectiva distintiva.

En su lugar, Kaviraj ha desarrollado una postura de corte más estructuralista. Para él, las estructuras son públicas y están por encima de la voluntad individual, a la cual moldean y limi- 
tan de distintas formas para crear un horizonte de posibilidades (Kaviraj, 1997a, p. 11). Como ya se indicó, Kaviraj argumenta que las élites colonialista y nacionalista crearon un consenso que considera las estructuras sociales tradicionales indias, como el sistema de castas, como inmutables. Tal tesis de la inmutabilidad se basa, según Kaviraj, en la dicotomía epistemológica occidental entre sociedades tradicionales, atrasadas, y sociedades modernas, en constante progreso; la cual le parece errónea. Esta falacia parte de una lectura equivocada de la narrativa política que sustenta ambos tipos de sociedades: mientras que las sociedades modernas abrazan una narrativa de progreso permanente, las tradicionales buscan ocultar los cambios que se están produciendo en ellas mediante una narrativa de estatismo temporal. La corrección de esa lectura errónea pasa, de acuerdo con Kaviraj, por adoptar un enfoque estructuralista, es decir, no detenerse simplemente en el estudio de la retórica y las narrativas políticas, sino también analizar la historicidad de las estructuras mismas.

Kaviraj comienza la aplicación de su enfoque estructuralista al desarrollo de la modernidad política india advirtiendo que el académico debe tener cuidado al utilizar la ontología política occidental en India (1997b, p. 231). Argumenta que, por ejemplo, en Europa los conceptos de Estado y soberanía son centrales para el desarrollo del poder político. El Estado como idea e institución política es desarrollada en Europa por necesidad histórica, es decir, es una demanda planteada primero por el absolutismo -el Estado soberano-y después por el liberalismo burgués -el Estado de derecho-. En India, sin embargo, es una imposición externa, no una demanda interna (Kaviraj, 1997a, p. 11).

Desde la perspectiva estructuralista de Kaviraj, no hay duda de que las ideas y las instituciones del colonialismo tuvieron una influencia decisiva e irreversible en el desarrollo de las estructuras de conocimiento indias al expandir el horizonte de posibilidades sobre la concepción del mundo social y su organización. En otras palabras, a través del colonialismo, India entró en contacto directo con las ideas de la modernidad occidental y con ello reestructuró su trayectoria histórica (Kaviraj, 1997a, p. 13). 
La naturaleza externa de las ideas políticas de la modernidad occidental produce tres reacciones cuando son introducidas en India a través del colonialismo. La primera es la resistencia pasiva, resultante de una incomprensión epistemológica y ontológica. La segunda es la resistencia activa, por poner en peligro las instituciones políticas, sociales y culturales. Y la tercera es la de incorporación de las ideas occidentales al imaginario indio (Kaviraj, 1997a, p. 12).

El resultado de la conjunción de estos tres tipos de reacciones respecto a las ideas de la modernidad occidental es, para Kaviraj, el desarrollo de una modernidad política india alternativa a la occidental. Según su argumento estructuralista, éste es el caso porque cualquier modernidad no se construye en el vacío, sino con base en instituciones y estructuras tradicionales que influyen en su desarrollo (2010, p. 11). Para estudiar el desarrollo de las ideas políticas de la modernidad india es necesario, por tanto, distinguir entre aquellas ideas e instituciones cuyo propósito era la subyugación colonial, y las que representaban los principios de la modernidad occidental. Este argumento puede ser ilustrado con el concepto de democracia. Kaviraj explica que la promesa del autogobierno indio formó parte del discurso ideológico del colonialismo tardío. Aunque esta propuesta nunca se cumplió, la democracia se convirtió en parte fundamental del imaginario político indio y, más tarde, del proyecto político de la India independiente (1997a, p. 14).

Como se ha visto, Kaviraj crítica el estudio de las ideas políticas con base sólo en el análisis discursivo, ya que los discursos son de naturaleza instrumental, construyen narrativas con un objetivo político en mente y no necesariamente revelan la realidad histórica. Tal análisis debe complementarse con un estudio de la historia de las estructuras políticas que desvele una fotografía más completa. En el caso específico de India, Kaviraj señala que la hegemonía historiográfica de la narrativa elitista nacionalista hace que el enfoque estructuralista sea aún más fundamental si cabe. 


\section{La corriente indigenista}

Junto con la hermenéutica, la otra gran corriente de estudio de las ideas políticas modernas en la ciencia política india es la que se podría llamar "indigenista", que se fundamenta en la tesis de la total separación histórica y epistemológica de las ideas políticas indias de las occidentales. Los indigenistas denuncian que, a pesar de la independencia política en 1947, India continúa bajo el yugo imperialista occidental debido a la hegemonía de sus categorías de conocimiento, que han permeado en todas las disciplinas de las ciencias sociales en el país. Para alcanzar la independencia verdadera es necesaria - afirman- la descolonización del conocimiento a través de la construcción de una ciencia política autóctona, basada en la tradición epistemológica india. Los miembros de esta corriente defienden la necesidad de construir una teoría propia de conocimiento unida a la de una identidad cultural independiente a la occidental, enraizada en la lengua y las tradiciones de la comunidad (Joseph, 1991, p. 960).

En 1931, Krishna Chandra Bhattacharya (1875-1949), profesor de filosofía en la Universidad de Calcuta, dio una conferencia titulada Swaraj in ideas, cuyo texto publicado posteriormente se convirtió en un manifiesto para los primeros indigenistas indios. En la conferencia, Bhattacharya denunció:

hoy, hablamos de swaraj o autodeterminación política. La dominación del hombre sobre el hombre se siente de modo más tangible en la esfera política. Hay, sin embargo, una forma de dominación más sutil en la esfera de las ideas por parte de una cultura sobre otra, una dominación mucho más seria en sus consecuencias, porque no es sentida de manera ordinaria [...] la esclavitud comienza cuando uno cesa de sentir el mal y profundiza cuando el mal es percibido como algo bueno (Bhattacharya, 1954, p. 103).

Bhattacharya buscaba hacer evidente el hecho de que, aunque se encontraban cerca de alcanzar la ansiada independencia, el proyecto de los líderes nacionalistas indios estaba basado en ideas e instituciones políticas occidentales; por tanto, no habría libertad porque intelectualmente la tradición de pensamiento india había sido remplazada por la occidental. 
La tesis indigenista de Bhattacharya ha sido desarrollada más recientemente en la ciencia política india contemporánea por un número de destacados autores. El principal exponente contemporáneo de esta corriente en India es V. R. Mehta, que en 1992 publicó Foundations of Indian political thought. En este libro busca, primero, examinar los distintos conceptos de Estado en la historia india de las ideas y, segundo, con base en dicho examen, desenterrar y articular una continuidad en la tradición de pensamiento político indio desde la Antigüedad hasta hoy.

Mehta entiende una "tradición" no como un pasado o una serie de preceptos inmutables y monolíticos, sino como un conjunto de prácticas y argumentos, a veces contradictorios, que interactúan entre sí a través de conceptos compartidos (1992, p. 9). Por ello defiende que las características distintivas de la civilización india, en particular en relación con su pensamiento político, aparecen a niveles profundos y no superficiales.

En primer lugar, Mehta argumenta que la identidad intelectual india nace de la tradición sociofilosófica védica. Señala que, a pesar de la diversidad lingüística, todas las lenguas del país poseen estructuras y vocablos similares para definir y articular conceptos sociofilosóficos védicos, como casta, deber o justicia (1992, p. 15). Esta conceptualización común, así como la geografía del subcontinente indio, contenido por el océano Índico al este, sur y oeste, y por el Himalaya al norte, son para Mehta las dos principales causas para justificar una tradición de pensamiento unitaria en India.

En segundo lugar, para Mehta es indudable que ha habido influencias externas en el pensamiento político indio, en particular la islámica y la occidental. Sin embargo, defiende que la civilización india se ha caracterizado, a lo largo de su historia, por su capacidad y disposición a la asimilación de otras culturas y otra gente. Basado en esa concepción integradora de la civilización india, que en su caso equivale a civilización hindú, el politólogo desarrolla su tesis indigenista: sí hay continuidad histórica en el pensamiento político indio, partiendo de la base védica, ya que la irrupción de otras epistemologías - como la islámica, la cristiana o la ilustrada- supone simplemente rupturas temporales de la linealidad de la tradición intelectual india; 
una vez que estas importaciones son asimiladas, la linealidad se ve restaurada (Mehta, 1992, p. 16).

La tesis indigenista de Mehta (1992, p. 268) presenta la tradición política india como "pluralismo integral". Este "pluralismo integral" está basado en el principio de la interacción entre unidad y diferencia. Un ejemplo que ilustra esta tesis es el concepto de swaraj, comúnmente interpretado como autodeterminación, pero ésta incluye tanto la autodeterminación política, es decir, la independencia nacional, como la individual, la liberación espiritual y física del ser humano. Para Mehta, el swaraj no puede ser equiparado, por ejemplo, con el individualismo occidental, porque, en la tradición védica, para alcanzar la autodeterminación individual es necesario cumplir tanto con los derechos como con los deberes que la hacen posible. Es más, los derechos sólo existen con el fin de capacitar al individuo para que cumpla sus deberes, y estos últimos lo conectan con sus funciones concretas dentro de la sociedad a través del sistema de castas, y lo relacionan con el proceso cósmico del que es una parte integral. En otras palabras, los deberes que emanan de la liberación individual o swaraj son la condición para la funcionalidad y el orden social. En ese sentido, afirma Mehta (1992, p. 268), el individuo en la tradición política india no es hobbesiano, sino que sigue el principio upanisádico de que es parte del todo y el todo es parte del individuo.

Thomas Pantham es otro de los académicos que han estudiado el pensamiento político indio moderno desde una perspectiva indigenista. En 1986 editó, junto a Kenneth Deutsch, el volumen Political thought in modern India. En la introducción, sostiene que el pensamiento político indio es intrínsecamente diferente al occidental debido a que está basado en suposiciones metafísicas y epistemológicas que difieren radicalmente de las del occidental (1986, p. 12). Pantham se apoya en la tesis de Mehta para argumentar que el pensamiento occidental está construido con base en una metafísica y epistemología dualista, sea ésta el dualismo cartesiano entre cuerpo y mente o el cristiano entre mundo físico y mundo espiritual. Para Pantham, este dualismo resulta en la legitimación del individualismo, la competición y la lucha amoral por el poder, sostenida sobre la división entre medios y fines, élites y masas o amigo y enemigo. Por su 
parte, el pensamiento político indio está construido con fundamento en una metafísica y epistemología holística en la que hay una interrelación entre el mundo físico y el espiritual, lo que tiene como consecuencia la promoción de comunidades sostenibles, la cooperación, la unidad humana y la ruptura de las dicotomías promovidas por el pensamiento occidental.

Pantham afirma la continuidad histórica esencial entre el pensamiento indio antiguo y el moderno (1986, p. 16). Sin embargo, es importante destacar que, al igual que Mehta, equipara pensamiento hindú con pensamiento indio, es decir, excluye como influencias externas no sólo las ideas occidentales importadas por los británicos, sino también las islámicas.

Un tercer proponente de la corriente indigenista es Ashis Nandy, cuya obra The intimate enemy (1983) supuso una auténtica revolución en el estudio del impacto del colonialismo en el desarrollo intelectual indio. La original tesis de Nandy es que la élite intelectual y las ciencias sociales en India han buscado reivindicar el esencialismo indio contraponiendo su tradición filosófica a la occidental, es decir, resaltando el carácter antitético de ambas. Para Nandy (1983, p. 73), tal intento del "no ser" es lo que verdaderamente fortalece esa influencia occidental en el pensamiento indio.

Nandy explica que hay dos identidades contrapuestas del indio moderno. Por un lado está la identidad del indio materialista, que desechó su cultura tradicional y abrazó la educación occidental para obtener puestos de prestigio en la administración colonial, con lo que se convirtió en colaboracionista por interés personal, tanto económico como de prestigio social. Por otro lado está la identidad del indio espiritual, construida desde una óptica orientalista, que se resiste al colonialismo refugiándose en la religión y la espiritualidad antigua y desechando el mundo materialista. Los académicos indios modernos - sostiene- buscan descubrir el verdadero carácter indio al desenmascarar una de estas dos identidades como falsa (1983, p. 82). Esta necesidad de los académicos de clasificar de manera nítida la identidad india es, para Nandy, un ejemplo de la influencia de la epistemología y las técnicas científicas occidentales en el mundo de las ideas en sociedades poscoloniales. Un segundo ejemplo de esa penetración epistémica occidental la encuentra 
en el desarrollo de una definición específica sobre lo que supone ser un hindú -o musulmán o sikh-: la necesidad de ser capaz de autodefinirse como tal en contraste con otras identidades religiosas o culturales. Para Nandy (1983, p. 103), esa necesidad de crear una autoconciencia identitaria o nacionalista proviene de la lógica occidental, no de la tradición lógica india.

Tales construcciones, denuncia Nandy, no conducen al desarrollo de una ciencia política autóctona india, sino a una mayor subyugación de la intelectualidad india a los parámetros de la ciencia política occidental. Para él, el desarrollo de una verdadera intelectualidad autóctona debe nacer del rechazo total a las categorías, enfoques y principios científicos occidentales y, en su lugar, se debe abrazar la ambigüedad cultural, identitaria y científica india. Nandy pone como ejemplo de dicha ambigüedad la Marcha de la Sal de Gandhi en 1930; su naturaleza pacífica, la falta de demandas políticas y el simple acto de la recogida de un puñado de sal con la mano, que luego sería arrojado de nuevo al suelo, resultaron ilógicos para la mentalidad política occidental de la administración colonial británica, cuya respuesta fue la represión violenta de los manifestantes. Para Nandy (1983, p. 106), es en la Marcha de la Sal donde verdaderamente se observa la diferencia entre las tradiciones políticas india y occidental.

Por último, Nandy habla de cómo el proceso de occidentalización de la población india que muchos intelectuales y académicos indios han denunciado con el objetivo de demandar un regreso a la tradición india, no es tal. Para él, los indios dividieron su ser en dos identidades: una exterior en la que actuaron como les pedía la administración colonial para sobrevivir físicamente a la represión colonial, y una interior que observaba a la exterior como un objeto, un escudo que protegía la esencia constitutiva del ser de la violencia y la humillación (1983, p. 109). Nandy define esta estrategia como psicosomática y pone como ejemplo modélico a los satyagrahi, que parecen aceptar sin resistencia la violencia y la humillación colonial, aunque verdaderamente se niegan a ser conquistados psicológicamente por el enemigo. ${ }^{7}$ Es esta lógica la que representa la

\footnotetext{
${ }^{7}$ Un satyagrahi es un activista político cuyas acciones reivindicativas se basan
} 
tradición política india autóctona, completamente independiente de la occidental, tanto es así que no comparte con ella bases epistemológicas ni lógicas.

En suma, la corriente indigenista en la ciencia política india busca reivindicar la autonomía de las ideas indias frente a la imposición de las occidentales por el colonialismo británico. Sin embargo, hay matices. Mientras que autores como Mehta y Pantham construyen sus tesis indigenistas con base en la lógica occidental, es decir, buscando la linealidad histórica de la tradición política india desde la Antigüedad hasta hoy, en el caso de Nandy su postura parte de un rechazo total al paradigma occidental, y la desarrolla en un marco cognitivo completamente distinto y, por lo tanto, desecha la posibilidad de un entendimiento entre distintas tradiciones epistemológicas.

\section{Conclusión}

La visión global de los distintos enfoques historiográficos que han analizado la interrelación entre las ideas y los valores políticos occidentales y el pensamiento político indio moderno es un ejercicio importante para comprender la naturaleza de la modernidad política, no sólo en India, sino en cualquier otra sociedad moderna. Toda modernidad se construye sobre conceptos políticos y, por tanto, es fundamental trazar el desarrollo de éstos en el tiempo para conocer la naturaleza de esa modernidad. En el caso de la modernidad india, dichos conceptos, como estos enfoques historiográficos buscan revelar, evolucionan desde su introducción por el colonialismo británico, pasando por su recepción y su reconceptualización por parte de la intelectualidad india, hasta dar forma al Estado-nación contemporáneo, el objeto de estudio de la ciencia política.

La principal conclusión a la que se llega es que la disciplina de la ciencia política en India está irremediablemente unida al movimiento por la independencia del país. La lucha por expulsar a los británicos del poder supuso que la ciencia política

en la resistencia pacífica. Gandhi fue el principal exponente teórico y práctico de esta forma de acción política durante el movimiento nacionalista. 
se convirtiera en una herramienta nacionalista más para construir una narrativa política a favor de la independencia, primero, y de la construcción nacional, después. Sólo hasta que el fervor nacionalista decayó, cuando el país se había asentado como Estado independiente y con la muerte del carismático Jawaharlal Nehru, la ciencia política comenzó a cuestionar la historiografía oficialista del nacionalismo y a expandir sus horizontes temáticos y metodológicos.

Esa expansión de horizontes en la ciencia política india contemporánea ha conllevado también la eclosión de un debate acerca de la recepción de las ideas políticas occidentales y su legitimidad a la hora de determinar el rumbo del Estado indio moderno, con dos corrientes claramente diferenciadas, la hermenéutica y la indigenista.

La corriente hermenéutica, que defiende que el pensamiento político indio moderno nace de la interacción entre distintas tradiciones epistemológicas que han cohabitado en India, incluida la occidental, se subdivide en tres enfoques historiográficos. Entre ellos, el de la escuela de Cambridge argumenta que hay una relación dialógica entre las ideas occidentales importadas por los británicos y las autóctonas indias, y que ambas se influyeron mutuamente. Los británicos adaptaron la teoría política occidental al contexto sociocultural indio para cimentar el Estado colonial, mientras que los intelectuales indios apelaron a los principios liberales para denunciar su ilegitimidad. Por su parte, los estudios subalternos postulan una continuidad entre las ideas occidentales y las nacionalistas y que ambas forman parte de la esfera de la élite gobernante. Por último, Sudipta Kaviraj defiende que, más allá del análisis discursivo, instrumental por definición, es necesario observar la naturaleza de las instituciones para determinar la verdadera influencia de las ideas occidentales en la India contemporánea.

La corriente indigenista, por su parte, aboga por la separación completa entre las ideas políticas indias y las occidentales. Algunos académicos indigenistas, como Mehta o Pantham, defienden dicha separación como histórica y epistemológica, es decir que hay una linealidad entre pensamiento político indio antiguo y moderno que no se rompe en ningún momento por la irrupción de las ideas occidentales. Otros, como Ashis Nan- 
dy, defienden la separación como necesaria en el presente para liberar a la ciencia política india de la subyugación de las categorías, los enfoques y los principios científicos occidentales, que son incapaces de reflejar la ambigüedad identitaria y la fluidez de la sociedad y los valores indios.

Desde mi punto de vista, resulta inverosímil concebir la trayectoria de la modernidad india como una cultura política monolítica históricamente, como sostiene la corriente indigenista. Sería ingenuo afirmar que el Estado colonial, que introdujo e impuso en India los principios del Estado moderno occidental - la soberanía única, la burocracia weberiana, el imperio de la ley-, no ejerció ninguna influencia en el desarrollo de la India posterior a 1947 y en los principios que la sustentan, desde el Estado de derecho hasta el secularismo. Igualmente, aunque los estudios subalternos aportan un enfoque esencial a la comprensión de la realidad política india, la crítica metodológica de Sudipta Kaviraj desvela una importante debilidad: cómo conjugar el reflejo fiel de la evidencia histórica y el testimonio subalterno con el uso de conceptos que no pueden expresar su contenido legítimamente, pero sin los cuales no se les puede incorporar al proceso de teorización política. Esta crítica la comparte el propio Partha Chatterjee (2012, p. 49) en una reflexión reciente acerca del fin del recorrido de los estudios subalternos como enfoque en el ámbito de la teorización política. Por último, la escuela de Cambridge, como señala acertadamente Nivedita Menon (2009, p. 11), peca al ignorar que la manipulación interesada de ciertas ideas por parte del Estado colonial dio lugar al desarrollo de realidades políticas impuestas a la élite intelectual india y que son fundamentales en el desarrollo de la modernidad política india. El ejemplo más claro es el surgimiento del comunalismo como fenómeno moderno de politización de la religión promovido por el Estado colonial y que representa un componente fundamental de la modernidad india posindependencia, desde la partición con Pakistán hasta la violencia intercomunal.

Finalmente, en el enfoque estructuralista de Kaviraj se encuentra una interesante aportación que, al destacar la naturaleza instrumental del discurso, sea elitista, subalterno o colonial, obliga a complementar su estudio con el de la evolución histó- 
rica de las estructuras políticas para descubrir la verdadera naturaleza de la modernidad. Así, el enfoque de Kaviraj ofrece una solución al impasse entre abstracción y relativismo, ya que permite realizar un proceso de análisis inverso en el que las estructuras políticas ayudan a exponer la correlación de fuerzas entre coloniales, derivativas y subalternas en la modernidad política india.

India es un caso de sociedad poscolonial exitosa en la que los principios liberales de democracia, secularismo y tolerancia se han consolidado. Por ello es importante prestar atención a los debates intelectuales que nutren allí epistemológica y ontológicamente a la ciencia política para comprender cómo sociedades complejas y diversas, pero con graves desafíos de pobreza y exclusión, son capaces de desarrollar sistemas políticos inclusivos y democráticos, es decir, legítimos.

Dirección institucional del autor:

Universidad Pontificia de Comillas

Calle de Alberto Aguilera, 23

28015 Madrid, España

\section{Referencias}

BAYLY, C. A. (1996). Empire and information: Intelligence gathering and social communication in India, 1780-1870. Cambridge: Cambridge University Press.

BAYlY, C. A. (2010). Epílogo. En S. Kapila (Ed.), An intellectual history for India. Nueva York: Cambridge University Press.

BAYLY, C. A. (2012). Recovering liberties: Indian thought in the age of liberalism and empire. Cambridge: Cambridge University Press.

BHANDARKAR, D. R. (1929). Some aspects of ancient Hindu polity. Benarés: Banaras Hindu University.

BHATTACHARYA, K. C. (1954). Swaraj in ideas. Visvabharati Quarterly, 20, 103-114.

ChatTerjee, P. (1986). Nationalist thought and the colonial world: A derivative discourse. Londres: Zed Books.

Chatterjee, P. (1996). Whose imagined communities? En G. Balakrishnan (Ed.), Mapping the nation (pp. 214-225). Londres: Verso. 
Chatterjee, P. (1 de septiembre de 2012). After subaltern studies. Economic and Political Weekly, 47(35), 44-49.

DandeKar, R. N. (1988). Artha: The second end of man. En A. T. Einbree (Ed.), Sources of Indian tradition, vol. I (pp. 231-252). Nueva York: Columbia University Press.

DAs, V. (1989). Subaltern as a perspective. En R. Guha (Ed.), Subaltern Studies VI: Writings on South Asian history and society (pp. 310324). Nueva Delhi: Oxford University Press.

DatTA, P. K. y Palshikar, S. (2013). Political Science: Volume 3: Indian political thought. Nueva Delhi: Oxford University Press.

Dumont, L. (1980). Homo Hierarchicus: The caste system and its implications. Chicago: Chicago University Press.

Gramsci, A. (2003). Selections from the prison notebooks. Londres: Lawrence and Wishart.

Gramsci, A. (2007). Quaderni de la carcere, vol. VI. Turín: Instituto Gramsci.

GuHA, R. (1982). On some aspects of the historiography of colonial India. En Autor (Ed.), Subaltern Studies I: Writings on South Asian history and society. Nueva Delhi: Oxford University Press.

GuHA, R. (1983). Elementary aspects of peasant insurgency in colonial India. Durham: Duke University Press.

GuHA, R. (1989). Dominance without hegemony and its historiography. En Autor (Ed.), Subaltern Studies VI: Writings on South Asian history and society (pp. 210-309). Nueva Delhi: Oxford University Press.

HeEsterman, J. (1985). The inner conflict of tradition: Essays in Indian ritual, kingship, and society. Chicago: Chicago University Press.

Hobsbawm, E. (1971). Primitive rebels: Studies in archaic forms of social movement in the $19^{\text {th }}$ and $20^{\text {th }}$ centuries. Manchester: Manchester University Press.

JAYASWAL, K. P. (2005). Hindu polity: A constitutional history of India in Hindu times. Nueva Delhi: Chaukhamba Sanskrit Pratishthan.

JosepH, S. (13 de abril de 1991). Indigenous social science project: Some political implications. Economic and Political Weekly, 26(15), 959-963.

KapILA, S. (Ed.) (2010). An intellectual history for India. Cambridge: Cambridge University Press.

Kaviraj, S. (1997a). Politics in India. Nueva Delhi: Oxford University Press.

KaviraJ, S. (1997b). The modern state in India. En M. Doornbos y S. Kaviraj (Eds.), Dynamics of state formation: India and Europe compared. Nueva Delhi: Sage. 
Kaviraj, S. (2010). The imaginary institution of India. Nueva York: Columbia University Press.

Khilnani, S. (1997). The idea of India. Nueva Delhi: Penguin.

Meнta, V. R. (1992). Foundations of Indian political thought. Nueva Delhi: Manohar.

Menon, N. (2009). Foucault and Indian scholarship: History, governmentality, modernity. Nueva Delhi: French Cultural Centre.

Nandy, A. (1983). The intimate enemy: Loss and recovery of self under colonialism. Nueva Delhi: Oxford University Press.

PANTHAM, T. (1986). Introduction: For the study of modern Indian political thought. En T. Pantham y K. L. Deutsch (Eds.), Political thought in modern India (pp. 9-16). Nueva Delhi: Sage.

Parekh, B. (1986). Some reflections on the Hindu tradition of political thought. En T. Pantham y K. L. Deutsch (Eds.), Political thought in modern India (pp. 17-31). Nueva Delhi: Sage.

PINCH, W. R. (octubre de 1999). Same difference in India and Europe. History and Theory. Studies in the Philosophy of History, 38(3), 389-407. https://dx.doi.org/10.1111/0018-2656.00099

SARKAR, B. K. (1939). The political institutions and theories of the Hindus: A study in comparative politics. Calcuta: Chuckervertty, Chatterjee \& Co.

SINGHA, R. (1998). Civil authority and due process: Colonial criminal justice in the Banaras zamindari, 1781-1795. En M. Anderson y S. Guha (Eds.), Changing concepts of rights and justice in South Asia (pp. 30-81). Nueva Delhi: Oxford University Press.

VAJPEYI, A. (2012). Righteous republic: The political foundations of modern India. Cambridge, MA: Harvard University Press. 
